\title{
12
}

\section{Making Inspiration Mainstream: Innovative Pedagogies for the Real World}

\section{Carina Buckley and Maria Kukhareva}

\section{Introduction}

Innovative pedagogies are those which represent a move away from 'established institutional practices' towards a more flexible, student-centred approach to learning and the learning space (Jamieson, Dane, \& Lippman, 2005), often born of a vision for what could be and dissatisfaction with what is (Lock, Kim, Koh, \& Wilcox, 2018). While an improvement in student engagement is often a driver for innovation and research (e.g. Haggis, 2009), that same drive can inhibit innovation through fear of unfavourable student feedback, reducing a willingness to take risks in delivery (Lock et al., 2018). Instead, we contend that a learning

Case studies: Christie Pritchard, Maria Kukhareva and Carina Buckley

\section{Buckley $(\bowtie)$}

Solent Learning and Teaching Institute, Solent University, Southampton, UK e-mail: carina.buckley@solent.ac.uk

M. Kukhareva

Organisational Development, University of Bedfordshire, Luton, UK 
development stance can support innovative pedagogies through its focus on student-centred working and embedding within the disciplines. Although innovation by definition ceases to be so when it becomes mainstream, we argue that innovation itself can be a mainstream activity, aligning the micro-, meso- and macro-environment of the university (Lock et al., 2018).

Learning development is an approach to higher education predicated on emancipatory practice and partnership working (ALDinHE, n.d.). In the context of an increasingly competitive higher education environment, it serves to enable the building of relationships with students, by helping them make sense of and get the most out of their learning (ALDinHE, n.d.). As such it has a central role to play in student engagement, since active student involvement in academic tasks and events is held to be vital for the success of their overall learning experience (Xerri, Radford, \& Shacklock, 2018).

Within a social constructivist pedagogy, engagement tends to be defined as active, interactive and observable behaviours, the performance of which will contribute towards the individual student's achievement in their learning (Gourlay, 2015). From this viewpoint, engagement, understood as the 'time, effort and commitment' given by students (Xerri et al., 2018, p. 592), is restricted to classrooms, where interventions planned by teachers are experienced by students (Zepke, 2015).

However, learning development's emancipatory standpoint requires that engagement be taken more broadly, to encompass the networks of social relations that bind students with staff, and peers with each other, and the resultant institutional culture (Xerri et al., 2018). In addition, as well as broadening out the theoretical approach to engagement from the individual, it must also go beyond the curriculum and beyond the classroom (Gourlay, 2015; Zepke, 2015) for reframing as a holistic and experiential approach to learning that promotes student transformation.

Innovative pedagogies that embrace ideas around real world learning support this reframing by focusing on authentic tasks that are situated and contextualised and which help to bridge the gap between theory and practice (Fig. 12.1). Where real world learning might more usually be taken to refer to live briefs, simulations and so on, in this framing the emphasis is more on a learning ethos of partnership working in 


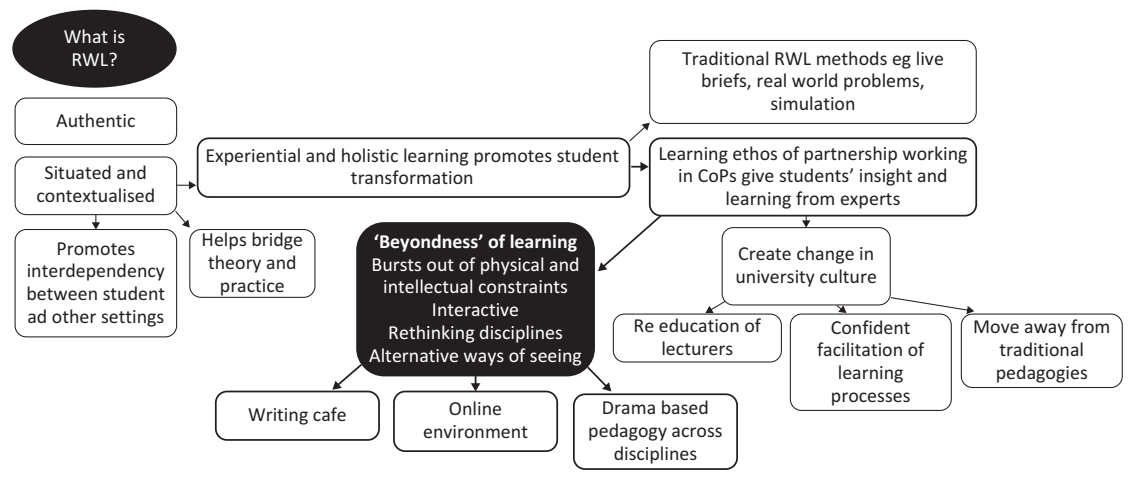

Fig. 12.1 Concept map from the authors

communities of practice, providing students with insights from the experts they work alongside.

This chapter presents three case studies of innovative pedagogies for real world learning that burst out of the physical and intellectual constraints that traditional pedagogies reproduce, however inadvertently. This 'beyondness' of learning allows for alternative ways of seeing through the crosspollination of disciplinary approaches, interactivity outside the subject group and flexibility in teaching spaces. We introduce a three-tiered model for innovative practice based on different conceptions of the teaching space through which flow three waves of innovation, in the physical space, the subject and the technology. The teaching space can be physical or digital, individual or institutional; in each case it is a space for roles and responsibilities to be negotiated and knowledge to be actively constructed.

These case studies reframe innovation as a mainstream activity for engagement, highlighting practices that while in themselves might be innovative in their approach or formulation, nevertheless are presented as standard and integral to the learning experience, thus keeping them real, achievable and effective.

Case study 1. How the University of Plymouth (UK) helps students learn beyond the classroom through an innovative Writing Café. Students can explore the discourse of academic writing from their own disciplines and experiences, breaking down conceptions of what it means to write at university. 
Case study 2. How the University of Bedfordshire (UK) facilitates student learning beyond the subject through drama-based pedagogies. Students can connect more deeply with their discipline through dialogic meaning-making and by drawing on affective and aesthetic learning domains.

Case study 3. How Solent University's (UK) SOL Baseline enables learning beyond the technology through a standardised, narrativebased approach to the virtual learning environment (VLE). Students can explore a rich, curated online environment that invites collaboration and interaction with peers and experts.

\section{What Do We Mean by Real World Learning?}

Real world learning has tended to be defined as an opportunity for students to work on projects or problems that have originated in the community or with a particular business or industry partner, such that students get to apply the theoretical knowledge they have learned to an authentic situation (Brundiers, Wiek, \& Redman, 2010). The benefit to the learning experience lies in the conjunction between the applied and the immersive aspects, whereby the students feel part of the (nonuniversity) working environment whilst undertaking the (non-university) industry-related tasks. Engagement is improved by locating learning activities within a social and experiential context, thus allowing richer opportunities for sense-making (Jennings, Cater, Hales, Kensbock, \& Hornby, 2015) that may be more complex and unstructured than the classroom environment would normally allow, often with the guidance of industry professionals (Theodosiou, Rennard, \& Amir-Aslani, 2012), and often with a significant affective component (Molderez \& Fonseca, 2017).

While this is what is most commonly understood by real world learning, this chapter expands it by including any types of learning spaces and 
environments that allow for more complex, non-linear engagement with the subject, discipline or topic, and which do not necessarily imply the involvement of industry professionals. We look for ways for real world learning to provide space for emotional and physical engagement with the discipline or topic, as well as intellectual.

Gardener (2008) proposes an idea of a "synthesising mind", as one of the "five minds" that will be "urgently needed" (p. 7) by our graduates in the near future, whose task will be, more than ever, to be able to work with a diverse range of information in a dynamic and rapidly evolving world. Howard also makes it clear, however, that the synthesising mind will be complementing rather than diminishing the value of the 'disciplined mind', which is associated with the narrower discipline-specific mastery.

We describe this process as the 'beyondness' of learning: going beyond the classroom learning, whether that is through the use of an extended learning space (Case studies 1 and 3), or beyond the discipline (Case study 2); or focusing on the physical space (Case study 1), the emotional space (Case study 2) or the collaborative space (Case study 3). These examples of real world learning are immersive and authentic, without being bounded by the requirements of specific industries. For example, Case study 2 uses theatre, imagination and play to help students deepen their learning, simulating real world contexts without the involvement of industry/subject professionals. The simulation goes beyond the subject and into the heart of the learner.

Emotional engagement is known to predict learning, which in turn supports academic achievement (Sagayadevan \& Jeyaraj, 2012), but for real world learning to be successful it must also be authentic, in that it must draw on and develop the same thought processes that a professional would use (Kreber, 2013), in activities that are socially framed and situated (Quigley, 2014).

Every individual is part of a community, and authenticity emerges when an individual engages in what Heidegger calls "public life" through discourse, which simultaneously interprets, constructs and constrains (McDonald \& Wearing, 2013, pp. 50-51). Authenticity in this context is not about "a deeper inner self" (Guignon, 2004, p. 125, cited in McDonald \& Wearing, 2013, p. 50) but instead is about finding 
meaning through the critical questioning of "the world outside ourselves" (Kreber, 2013, p. 26). Our tendency is to see ourselves as separate from the community - "the they" — rather than also being one of the constituents of that community, so that the focus remains on individuality rather than the "collective formation of social roles" (Stroh, 2015, p. 254). Ironically, it is through the distance created by this individuality that we come to understand our "being-a-community". This is the key to authentic living (Stroh, 2015, p. 256).

Using Heidegger's ideas around Being and 'the they', Kreber (2013) suggests that authenticity in a teaching situation relates to experiencing what feels most true or real. By extension, those learning in an authentic real world situation could therefore expect to be able to examine their own values and ideals, more than simply the content of that learning. Being able to do so, and indeed demonstrate their values and ideals to others, is a central component of an increased sense of authenticity in oneself. Therefore, teaching students how to interpret and construct meaning, rather than delivering content, supports authenticity by helping them recognise that they have an active role to play in the community. When we as educators impose learning upon them, we have failed to realise that the students have a part to play in determining the nature of that learning.

Authentic real world learning, therefore, contributes to and supports individual authenticity through the opportunities it provides for social contact and positive affect (Lenten, Slabu, Sedikides, \& Power, 2013).

\section{Transformation in Student Learning: The 'Beyondness' of Learning}

As mentioned in the introduction, we are presenting our take on innovation through a three-tiered multidimensional model, which captures the cross-sectional and cross-disciplinary nature of pedagogical activity in our case studies. The model (Fig. 12.2) draws attention to the way innovation is perceived: it suggests how traditional boundaries can be crossed 


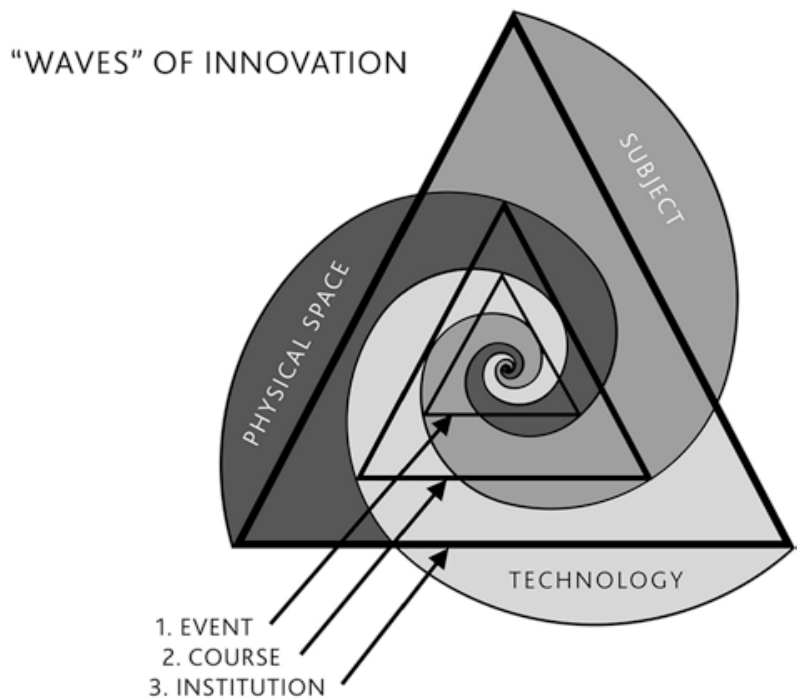

Fig. 12.2 Model for the dynamic interdependence of learning spaces and sites of innovation

and blurred, and how knowledge and practice can be shared, while maintaining the existing structures.

In Fig. 12.2, the triangles represent the 'levels' across which innovation takes place or, in other words, the scale of innovative activity. The innovative practice can occur at a single/multiple event level (small triangle in the centre) or at a course level (larger triangle) or at the level of the whole institution (largest, external triangle).

The spirals in the model can be viewed as 'waves' of innovation, the domain in which (or perhaps, beyond which) innovative activity occurs. In our case, it is the domain of subject (mid-grey spiral), the physical space (dark spiral) and the technological space (pale spiral).

The model also allows the capture of various 'shapes and sizes' in which innovative activity can occur. The visual illustrates that although innovation may start at any level and be taken forward by different teams across a range of areas of learning, there is potential to continue crossing the boundaries further, expanding and embedding innovative approaches into teaching and learning development. We would like to propose that 
a partnership cross-team approach is key to first seeing innovation as a mainstream activity and then making it happen.

Thus, our first case study proposes a way to enhance student learning by taking them physically outside the classroom and into a stimulating learning environment in a Writing Café, for the whole course cohort. This is represented by the dark 'physical space' spiral and the second largest triangle on the diagram.

The second case study focuses on an interdisciplinary collaboration, which takes the students temporarily outside their subject, and invites them to engage with their discipline through drama-based learning methods and techniques, through a series of workshops, designed by a crossdisciplinary team of professionals. In the diagram, this case study is represented by the mid-grey spiral (subject), taking place at the level of an event (central, smallest triangle).

The third case study in this chapter details the process of developing and implementing an innovative technological approach to student learning (the pale spiral) across the whole university (the largest, external triangle).

The 'beyondness' of learning is a tool for authenticity. The interplay between the site and the medium of innovation serves to expand and make explicit a learning community that exists beyond the immediate experience of the student. All three case studies present a different way in which the alienation of the individual from the community is overcome, creating a means by which the student can negotiate their role and construct knowledge alongside others. Each case study presents a different strategy but with the same goal: complex, dynamic and situated learning environments that value student-centred, emancipatory practices.

\section{Situated Learning: Beyond the Classroom}

Situated learning arose as an instructional method that would enact the link Lave and Wenger (1991) had originally observed between cognition and the environment, in a process that they termed 'legitimate peripheral participation'. In this model, those new to a field learn it by taking part in it in the presence of more experienced others. They are exposed to the 
discourses, resources and practices of the community not as an observer but as a participant, negotiating their engagement through the building of relations between themselves and other practitioners, and themselves and the field. In this relation-based understanding of learning, the student comes to understand themselves as a practitioner and a member of the community through having themselves recognised as such by others. Identity is essentially social in nature, and the successful adoption of a new identity such as 'student' means to adopt the socially negotiated goals, behaviours, values and ways of thinking and feeling of that identity (Ashforth, 2012).

To learn therefore means to participate in a social community of other learners, interactions with whom allow for the development of one's identity. Hwang, Chang, Chen, and Chen (2018) emphasise the value of situated learning for problem-solving, in that the context itself becomes a participant, framing and reflecting the issues and perspectives that the students bring. In this way, simply being a part of the community is a valuable contribution to learning in that the more it is experienced, the more richness there is in how it is experienced (Callary, Werthner, \& Trudel, 2012).

In Case study 1, the Writing Café at the University of Plymouth is a space that frames and supports the development of students' academic literacies in a real world, authentic way. It does so through its valuing of community and collaboration, with students learning from each other and the tutor providing 'cognitive apprenticeship through modelling, coaching and prompting for further reflection' (Hwang et al., 2018, p. 1201). Students spend time with others engaged in writing and taking part in salient and authentic activities and discussions, and in doing so learn to develop the identity of 'writer'. The learning space is studentcentred and experiential, removed from the bounds of both course and subject.

\section{Case Study 1}

The Writing Café as an innovative space (Christie Pritchard, Student Learning Manager, University of Plymouth, UK) 
A large slate globe sits on the edge of the worn desk, piles of old books are scattered all around and the Penguin book cover wallpaper is illuminated by a large floor lamp. The furniture is old; each piece has had a former life, perhaps in someone's home, the marks of their stories still present. The aroma of coffee and toasted teacakes fills the air and there is a sense of purpose in the atmosphere. This isn't the scene you would usually find in a post-1992 university, but it is what greets you when you enter the Writing Café at the University of Plymouth. The physical space can be considered as a performative space, where interactions between the tutor and student occur (Barnett, 2011; Bennett, 2006). The spatial 'norms' of these areas continue to be influenced by the pedagogic principles of the 1960s and 1970s and are still dominant with building planners today (Bennett, 2006). As such they privilege some learning activities over others (Temple, 2008), therefore making the practice of student and staff partnerships challenging. Traditional institutional architecture provides an optimum environment for teacher-centred practices, and the delivery of content to students, but the Writing Café was founded on the belief that much learning takes place between places, in social areas, cafes, corridors, walks across campus and residential areas. In this sense the Writing Café is a real world environment where the physical space underpins the intended pedagogy and disrupts the privileged positioning of the 'expert'. Much like its historical predecessor, the coffeehouse, the space forces dialogue, collaboration and debate.

The concept of the Writing Café was to move away from individual one-to-one support provided by a Learning Developer with a student to creating a multidisciplinary environment for discussing ideas and sharing drafts of writing. By having Learning Developers, trained Writing Mentors and students sit around a table, disciplines and levels of study collide and the boundaries between the expert and the novice are shifted as each can explore the discourse of academic writing from their own disciplines and experiences. Along with serving great coffee and locally sourced food, conversations and activity in the Writing Café have ensured that both novices and more experienced writers are able to learn about writing together (Carnell, MacDonald, McCallum, \& Scott, 2008). This is because any 'stumblings and violations' incurred are not just characteristic of novice writers, but are features of writing itself and they may be 
obscured if there is no discussion of writing-in-progress (Wenger, 1998 cited in Murray \& Newton, 2009, p. 550). In this sense, the Writing Café contributes to the demystification of writing, where social experience, openness and dialogue encourage people to explore techniques to improve their own approach to writing, and their understanding of knowledge production.

The Writing Café is considered as a purposeful space that can provide an opportunity for all involved to 'overcome the challenges and obstacles in their efforts to write effectively and productively' (Moore, 2003, p. 333). It was an attempt to disrupt the status quo of supporting the development of academic writing within higher education in an instrumental way and in a sense provide a different space that legitimised an academic literacies approach (Lea \& Street, 1998). Over the last 30 years, the growing body of research that examined the notion of academic literacies (Barton \& Hamilton, 1998; Lea \& Stierer, 2000; Lea \& Street, 2000; Street, 1984) problematised the belief that literacy, including academic writing, is a set of skills that can be taught and acquired by students and therefore applied in numerous contexts outside of their studies (Lea, 2004). Since its initial conception the debate has evolved and has demonstrated how literacies cannot be reduced to a set of cognitive skills as they have different identities and 'literacy practices are what people do with literacy', thus 'practices are not observable units of behaviour since they also involve values, attitudes, feelings and social relationships' (Street, 1993, p. 12). Whilst our theoretical understanding of academic writing may have progressed, many of our university campus spaces, practices and services have not. If we consider academic writing in this manner, then we also need to explore and uncover these complexities of social processes and practices being culturally and spatially bound and varying in different environments, disciplines and contexts (Lea, 2004). The Writing Café is a place dedicated to doing just that. Rather than solely focusing on 'good and bad' educational judgements about a student's writing, like a bolt-on study skills model, our practice takes into account the complex and intertwined discourses and power relationships at play within the institution and in student learning.

All members of the community are working together to interpret meaning and co-construct knowledge and whilst this does not take place 
with every student we meet, the Writing Café aims to support students and staff to consider both the implicit and explicit practices of higher education and encourages individuals to value their own position. It contributes to the demystification of writing, where social experience, openness and dialogue encourage people to explore techniques to improve their own approach to writing, and crucially their understanding of knowledge production. The space supports these discussions and interactions, emphasising the pedagogic approach and providing a real world environment in which this learning can take place.

\section{Imagination and Emotion: Beyond the Subject}

The proposed 'waves' of innovation model also allow for capturing innovative practice that can go beyond the discipline (in our case, the pedagogy of the discipline) at the level of an event (in our case, a timetabled workshop). In other words, we point to ways in which educators can create opportunities for "beyondness of learning", which invites the students to draw on their contextual thinking, defined by Repko et al. (2017, p. 7) as the "ability to view a subject from a broad perspective by placing it in the fabric of time, culture, or personal experience". Connections can also be made here with the authors' reference to 'integrative thinking', whereby students are asked to integrate their subject knowledge and their personal experience, in order to respond to the task presented by the facilitator.

With this in mind, Case study 2 illustrates how drama-based methods have the potential to help the students to connect with their discipline of choice, through creating deeper and more personalised, and therefore meaningful and even transformative, learning experiences. In this respect, Davis (2015) states that transformative learning can occur through activities, through which participants "come to see aspects of the world or themselves in new ways, and where the meaning making may lead to changes in consciousness, in beliefs and actions". Davis's work draws on Vygotsky's concept of perezhivanie (see Fleer, Rey, \& Veresov, 2016; Rey, 2016), a term that can be translated as 'living through', or 'reliving' an experience, which is described as the second most authentic state after the 
real experience itself. Drama-based methods are designed to activate the state of perezhivanie, which draws on the affective and relational domains, thus creating "affirmative injunctions" (Allan, 2013, p. 37), which then affect students' intrinsic motivation and results in deeper learning (Fleer et al., 2016; Rey, 2016).

\section{Case Study 2}

Facilitating student learning beyond the subject through drama-based pedagogies (Maria Kukhareva, Head of Organisational Development, University of Bedfordshire, UK)

This case study presents an example of real world learning whereby students were invited to engage with the subject knowledge through the method of drama-based pedagogy, which would traditionally 'sit' outside the subject domain. The approach that was developed would not have been possible without a partnership approach to student learning and development, as it drew on expertise from three distinct parties: the teaching and learning team, the disciplinarians from the Business school and an artist (theatre director). The aim of this collaboration was an initial exploration, followed by the design of an innovative pedagogical activity that goes beyond the traditional realms of a single discipline (presented as the mid-grey triangle in Fig. 12.2) and thus promotes transformational learning through creating authentic, engaging and possibly surprising experiences. The resulting teaching methods were applied within scheduled workshops (the 'event' level in the model) across several subjects in the institution's Business school, which invited experimentation within the established boundaries of the curricula and the unit. This case study offers an insight into the design that underpinned the 'beyond the discipline' innovative approach in the classroom, and invited students to expand their own expectations and understandings of their approach to learning 'in the discipline'.

The drama-based pedagogy approach can be presented as a set of crossdisciplinary teaching tools. These tools_-for example, image work, role work and metaphor - allow educators to draw effectively on the students' affective and aesthetic learning domains; this leads to deeper engagement 
with the topic through dialogic meaning-making (see Dawson \& Lee, 2018). While this method can be highly enriching and complementary across the curriculum, it also has potential to challenge the students' expectation of the scope of their discipline and the associated teaching methods. In other words, drama as pedagogy can act as a catalyst for learning development, which encourages the students to go beyond the subject - with the view to later return to the subject, with a broadened and deepened knowledge and understanding of the latter.

For these new approaches to be effective, all educators in the crossdisciplinary partnership went through a process of intensive, iterative and reflective learning from each other. A shared value of students' learning development supported the partnership ethos. This open collaboration led to the necessary method transfer between the three expert groups: from teaching drama (artistic theatre director) to drama pedagogy (teaching and learning) and to 'teaching in the discipline' (subject specialists in law, marketing, tourism management). The resulting approach, therefore, possessed certain interdisciplinary features - as it emerged as an amalgamation of drama-based pedagogy and 'teaching in the discipline'.

As part of this reiterative dialogue, aspects of curricula were explored through the lens of enhancement through the 'infusion' of drama-based pedagogy, with a view to increasing student engagement and interactivity. The lecturers' teaching disposition and facilitation style were also considered, as this would affect the delivery and impact students' engagement and learning. Overall, seven new workshops were designed and delivered across the three subjects. Figure 12.3 captures the iterative method design process.

The reviewed material, which lent itself most organically to dramabased pedagogy, was closely linked with the 'real world' examples and case studies. Indeed, subjects such as law, tourism management and marketing and communications arguably have a strong emphasis on practice as part of their curriculum already. However, drama-based pedagogy may offer students more unconventional ways of accessing elements of real world learning, without leaving the classroom, as it creates powerful learning opportunities through imaginative, emotive and dynamic work.

In our case, tools such as activating dialogue, image work and role work were used to facilitate the process of learning and knowledge 

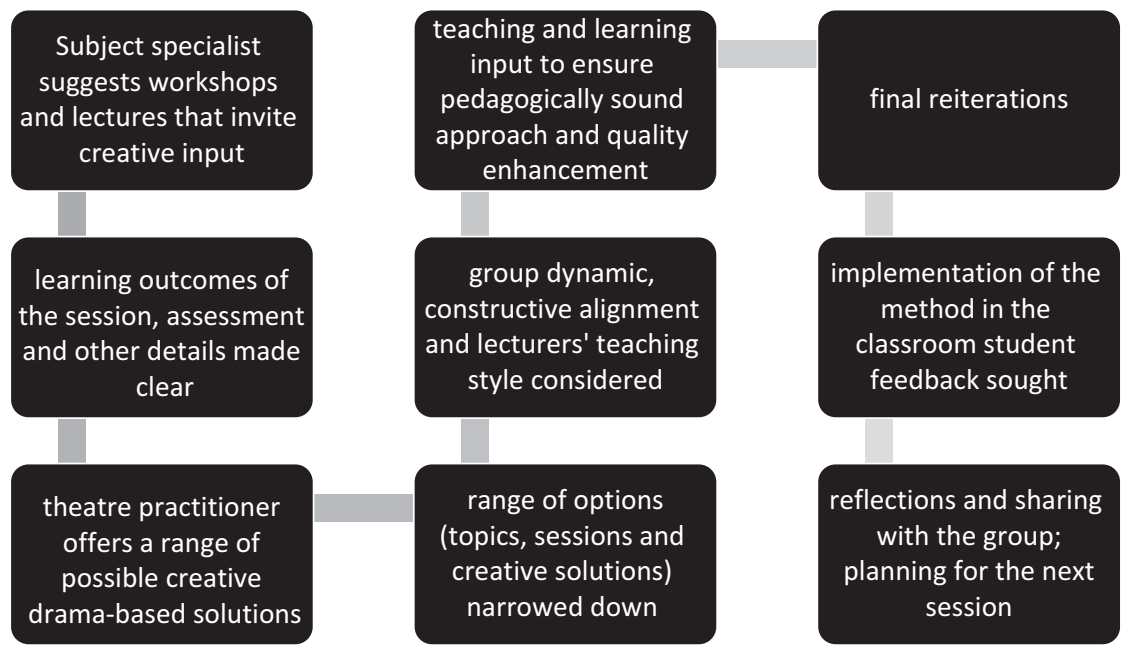

Fig. 12.3 Reiterative process of workshop development

construction. These tools were used in place of pair and group discussions-both effective active learning tools, but arguably less dynamic and interactive (from the embodied and affective learning domain point of view) than the drama-based methods. That said, it was important to scaffold the activity, by gradually increasing the interactivity, to make dramabased learning more comfortable for the students. Indeed, having an open mind with regards to how the subject is being taught may be a challenge for some students (as well as academics), as they may be coming with relatively fixed ideas about their discipline of choice, and, within that, learner identity, which presents "a stumbling block for learners in taking interdisciplinarity on board” (Dalrymple \& Miller, 2006, p. 30).

For example, law students were asked to complete a series of activities, aimed at deconstructing, reconstructing and 'layering' their understanding of a legal case study presented to them. As this legal case study formed a part of their upcoming assessment, detailed understanding of the key facts as well as the context was crucial to the students' achievement. Each task was followed by a discussion, facilitated in the format of Socratic dialogue (questioning), to encourage reflection and create an opportunity for deeper learning. The model in Fig. 12.4 illustrates the activity. 


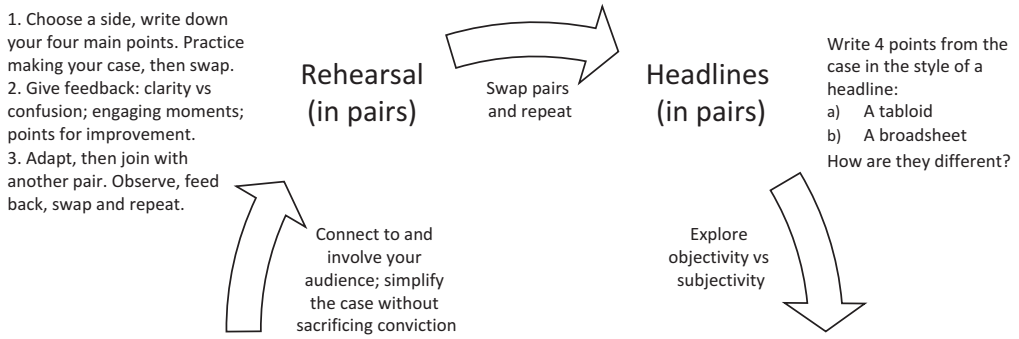

As Claimant or

Respondent, create a children's story of the Storytelling case. How do you create (2 pairs) dramatic climax? How should you pace it?

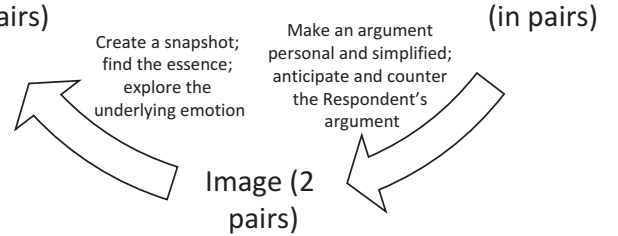

Letter/email

Write an informal letter as Claimant to a friend covering what you wil say in court and how you will argue against the Respondent.

Fig. 12.4 Task-based reflection for assessment

Similarly, students studying marketing and tourism were offered to connect with the subject content through role play, activating dialogue, image play and even poetry. The activities were scaffolded, with each step building on the previous, and continuity of the imaginative process emphasised by the lecturer. The students were learning to connect with their discipline of choice through creating deeper and more personalised and therefore meaningful learning experiences. Although some were hesitant at first, they were surprised at the realisation that although 'it didn't feel like learning', they seemed to have retained a complex topic at the end of what seemed to be 'playing' that didn't appear to be directly related to their discipline.

Davis (2015) offers an explanation of this phenomenon, stating that transformative learning can occur through activities by which participants "come to see aspects of the world or themselves in new ways, and where the meaning making may lead to changes in consciousness, in beliefs and actions". After all, the students were using the methods that professional actors use in order to live and become the character they'll play on stage. It is important to mention here that although the students 
were offered an approach that went beyond their understanding of what their subject entails, the majority were positively surprised by their own as well as their classmates' creativity, and the feeling of 'learning while not learning'. The law students, who completed drama-inspired exercises in preparation for their assessment, stated that they felt more confident and prepared; the assessment results supported this suggested impact, which was a truly positive development. The success of this development was grounded in all parties' commitment to the cross-disciplinary partnership working, new learning and knowledge transfer, and willingness to innovate. Once developed, the approach and accompanying materials can be sustained by embedding them into the curriculum, thus pushing the 'beyond the subject' wave from 'event' level into 'course' and possibly even 'institution' level.

\section{Collaboration and Construction: Beyond the Technology}

Up to this point, community has been taken as a physical entity, its members interacting face to face and the networks of social relations having a tangible structure. Nevertheless, a learning environment can go beyond the physical classroom. Social constructivism holds that learning takes place when learners have the opportunity to explore, negotiate and construct their own understanding; it doesn't require that this takes place in person, simply that there is opportunity for learning to emerge through discussion.

Virtual learning environments (VLEs), like Moodle, are built on the principles of social constructivism (Moodle, 2012), and the collaboration this involves is mediated by the tools and affordances of the technology, within the necessary context of a community. Just as in a classroom setting the imparting of content is held to be inauthentic, so too in the online learning environment should learners be able to interact in a discursive context in order to negotiate meaning (Lambropoulos, Faulkner, \& Culwin, 2012). Learning is therefore active rather than passive, with students engaged in an ongoing process of building, adjusting and 
consolidating knowledge based on what has gone before (Lindgren \& McDaniel, 2011). As with all communities of practice, this can only succeed when the community members act as though they were members of a community (Stroh, 2015). If a VLE is set up as a community space, then its users are more likely to recognise it as such and act accordingly.

Case study 3 showcases the transformation of an institutional virtual learning environment (VLE) into a site for collaboration and discussion through the active participation of both staff and students in a learning community. For this to succeed required a change to the institutional culture, to bring that same student-centred approach to the learning space that existed in the classroom into the online environment.

\section{Case Study 3}

The SOL Baseline and authentic engagement beyond the technology (Carina Buckley, Instructional Design Manager, Solent University, UK)

In July 2016, Solent University introduced a goal for all courses to become 'Blended by Default', through a standardised approach to learning and teaching that would take full and seamless advantage of all the strengths of classroom and online learning. The first move towards this was the development of a template in Solent Online Learning (SOL), the VLE delivered in Moodle, that would be automatically applied to all modules each academic year. The initial purpose of the new template was to encourage greater consistency in the presentation of individual modules, to help ensure every student had access to the same online experience. However, it quickly became apparent that the move to a fixed template carried greater opportunities than originally anticipated. Accordingly, the SOL Baseline model emerged as a way to deepen and contextualise the template (Fig. 12.5).

The innovative approach came in how the Baseline imagines-and provides the potential for-each individual module to become a site for a collaborative learning community, in its own right and also as part of a networked web of modules encompassing a course, a programme or even a subject group. Up until that point, SOL had been used principally as a 


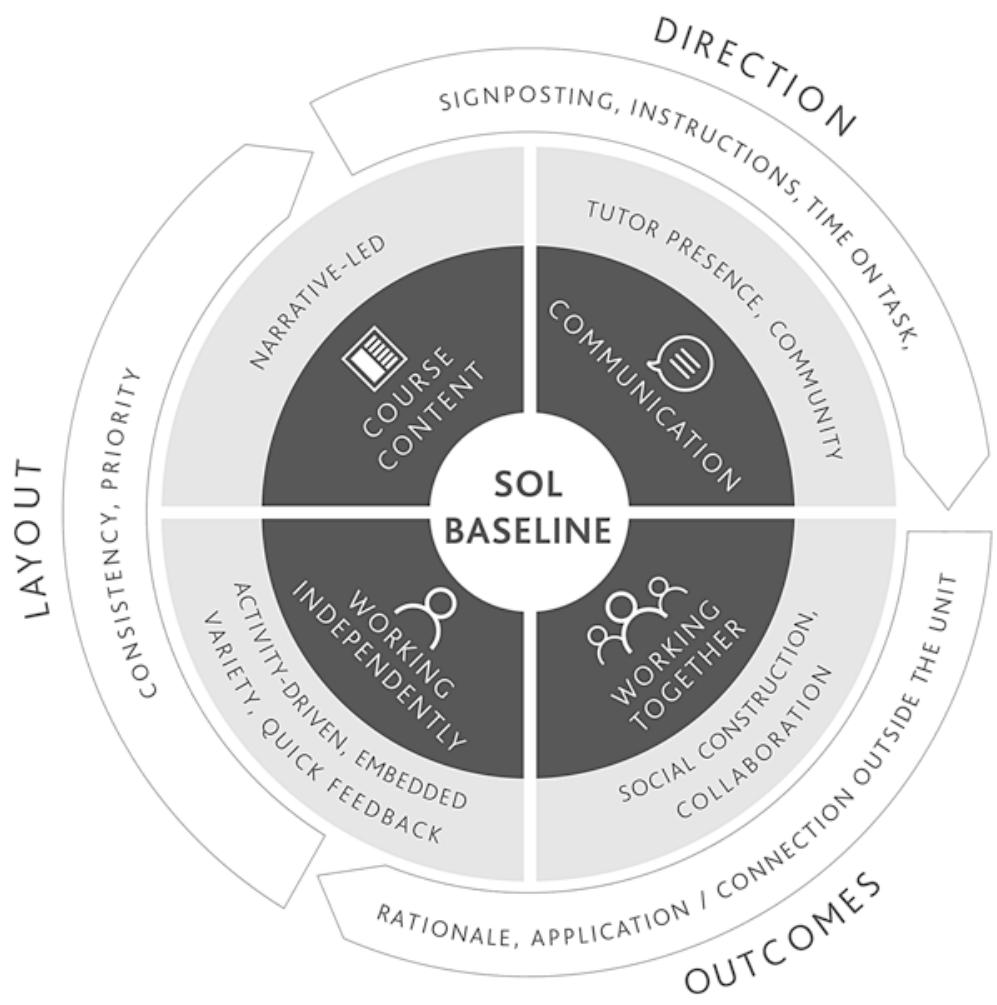

Fig. 12.5 The SOL Baseline

file repository and often viewed with mistrust by lecturers who saw it as a means for their replacement. It was a radical change, therefore, for the SOL Baseline, in contrast to those fears, to take a structured approach towards building a true learning community, where staff and students could interact and learn from each other. The ultimate goal was to provide a rich and valued learning experience beyond the classroom, with the focus becoming what the students were learning and how, rather than where. Real world learning in this instance, therefore, refers to authenticity in engagement.

For the SOL Baseline to break free of the technology and embrace the VLE as a site for pedagogic change and authentic learning, it would be necessary to make more coherent links with the physical teaching spaces 
and the people in them. As such, the whole direction of the SOL Baseline moved towards the relationships and interactions between tutor and student, and between peers, whether they were situated online in SOL or in the classroom. The VLE became engaged as a tool for challenging and changing learning and teaching culture across the university.

At the heart of the Baseline are four principles through which staff and student agency may be enacted: Communication, Course content, Working together and Working independently. By giving clear signposting through the unit, with rationales for each task or learning object, the lecturer can direct the students' learning and maintain their presence without needing to be physically present. The same precept is applied to the way course content is presented, with the Baseline endorsing a narrative-led approach. This means that files, videos and other resources are contextualised and linked, making SOL dynamic rather than static. The lecturer becomes a curator of teaching and learning materials, their expertise harnessed to create authentic, real world learning. In a world increasingly characterised by information overload, the Baseline asks lecturers to help students discover what is essential for their course.

Over time, the Baseline has developed further, through the exploitation of the affordances of the technological tools. Assessment briefs are now recorded as a video by lecturers, which is uploaded onto the module page but also shown in class and used for a discussion activity to check students' understanding of the assessment requirements. Originally introduced as part of a project to reduce the attainment gap between Black and minority ethnic (BME) and White students, it serves a greater and more holistic purpose in acting as a counter to the alienation students can feel from the community, in this case through the discourse of the academy.

The introduction of new interactive elements has likewise empowered students to take more control of their own learning and increase opportunities for peer engagement. SOL becomes a safe space in which to be challenged and supported, collating resources_-including and especially people-that can help students achieve their goals. However, this is not to say that the value of the SOL Baseline is in the technology it uses. Authentic, real world learning means going beyond the technology, and for SOL that equally means the provision of texts or other resources that 
are explored by the students in their own time and made use of in the classroom, in a flipped approach. The overriding principle is the holistic nature of the SOL Baseline; it applies to the learning environment generally, whether that is online, in a classroom or out in the field. Its value lies in the social networks it embodies, rather than the medium through which it embodies them.

An innovation that was introduced at institutional level, the SOL Baseline has succeeded because it has gone beyond the technology to encompass the physical space and how the subject is taught there. In doing so, it has changed the conversation around teaching and learning at Solent University.

\section{A Learning Development Approach to Real World Learning}

A learning development approach is inherently student-centred, within a broader emancipatory context that recognises and, if necessary, challenges the social relations that together make up an institutional culture. Rather than replicate and reinforce systems that alienate the individual from the community, such as the deficit model that problematises the student's abilities, learning development instead looks to champion practices that go beyond the individual student to embrace the learning and teaching culture as a whole.

The three case studies outlined in this chapter all have a learning development perspective, putting the student at the centre of cross- and multidisciplinary practices. All three recognise that knowledge is constructed by each individual in collaboration with others. Knowledge becomes an activity rather than a possession; it becomes something that people do, rather than have. At the same time, knowledge is not "value-free, decontextualized, neutral and apolitical" (Morrice, 2009, p. 8, cited in Sinfield et al., 2011, p. 54) and therefore neither should the means of constructing it be considered in those terms. "Knowledge emerges only through invention and reinventions" (Freire, 1996, p. 53, cited in Sinfield et al., 
2011, p. 55) and it is the task of learning development to enable those reinventions if the students are to experience true authentic learning.

Thinking specifically about real world learning, these innovative approaches all constitute ways of achieving authenticity: collaboration through discourse, collaboration through shared meaning and collaboration through activity. These collaborations are not restricted to a classroom or a discipline group, but instead can take place at all levels of the institution, through a variety of modes.

The Writing Café in Case study 1 is a multidisciplinary space in which students can explore the discourse. It moves academic writing from an instrumental, skills-based task to a set of literacies and practices that must be embodied and performed. Even so, this is not something that is done to the students. Meaningful collaboration requires that hierarchic structures are flattened as much as possible (Sinfield et al., 2011) and in the Writing Café, this means peer-led support. The boundaries between expert and novice are blurred, and the student gets the chance to engage as an equal member of a community. By sharing the space with staff as well as students they get to participate legitimately, not simply peripherally but also centrally, in a professional, situated setting.

The collaboration in Case study 2 takes place amongst three expert groups of staff in an interdisciplinary enterprise. Working together, they create a space that engages students emotionally as well as intellectually, and which allows them to connect with each other and with the subject through the process of making meaning. The authentic nature of the activity comes through in the way that they, as Davis (2015) says, "come to see aspects of the world or themselves in new ways". More than that, it is argued from our Heideggerian perspective that by working authentically, they come to see aspects of the world in themselves. Through being given a chance to recognise their individuality in a personalised learning experience, it opens up the opportunity to see the community of which they are a part. Drama, and the taking on of another character or personality, is a way of exploring the world through alternative perspectives and being able to test out what feels 'true' or 'right' in a particular situation. In playing a role, they construct meaning for themselves but also for those who get to see the performance. 
Finally, Case study 3 took a medium that arguably could, used badly, increase alienation and isolation (Holley, Burns, Sinfield, \& Glass, 2011) and ameliorated the risk by providing for the development of a collaborative learning community that has the potential to reach far beyond the module. The biggest danger of this approach was that it would lock the student and the lecturer into a resource repository, knowledge and learning constrained by the technology. However, the emphasis on narrative and context counters this by bringing in the personal and showing the student that the lecturer shares the space. Those lecturers that use the space best do so by sharing their interests, pointing out problems or puzzles and encouraging students to share their ideas with each other. Students, in this enriched environment, gain power and choice in their learning; the emphasis shifts from where they learn to what they are doing and who they are with. They are fully embedded in the community, and the learning environment is a blend of the online and the physical.

The value and rewards of community-based authentic learning are what make these three strategies so worth pursuing. All of them contribute to an ethos of partnership working and crossing boundaries, and all of them work to normalise these innovative pedagogies and make them mainstream. That is not to say they are easy to institute. Good partnership working requires at least one like-minded other, as well as an institutional culture that allows them to work together. These pedagogies also require space: to plan and to enact. Physical space is inextricably linked to the subject and the technology, the degree determined by the level at which the innovation takes place, whether that is a single class or across the whole institution. To roll out these innovations and bring them into the mainstream means being able to see the interplay between the scale and domain. This is the site of the learning community, and this is where the opportunities reside that each provides. 


\section{Conclusion}

We have proposed in this chapter an approach to viewing innovation as a mainstream activity, and in doing so have presented a way to increase student engagement through the dynamic flexibility of the innovation model, from a learning development perspective. We chose to do this for several reasons, not least because we felt that it was necessary. When we look at UK higher education, we take in a view of boundaries becoming increasingly blurred between learning spaces and places, and ever more emphasis placed upon the dynamic nature of learning and the growing focus on collaboration and knowledge exchange. In this environment, real world learning presents itself as a productive model to pursue as the boundaries between the university and the world outside become similarly porous.

We also saw the necessity from the point of view of the student as a person in the world. Our approach is a route to achieving authenticity in learning and therefore a stronger connection to it. Fully situated and contextualised tasks, within an ethos of partnership working, take students beyond the constraints of place and subject and into a broader and deeper learning space that takes in the whole person.

The model introduced in Fig. 12.2 presents learning as a non-linear event constituted by one or more domains and which may take place at one or more levels. It aims to reinforce the importance of recognising innovative approaches in higher education practice, and then identifying how these approaches can become part of mainstream activity. We argue that the three case studies presented here, while framed as innovative pedagogies, all have the potential to become mainstream and fully incorporated into what we understand as good learning and teaching. The main mechanism for doing so is via the learning development lens and its emancipatory emphasis on social relations.

The three case studies, all grounded in real world learning, were purposefully chosen for their differing nature and institutional application. They illustrate how innovative approaches can emerge from any corner of university practice, yet the underpinning rationale and methodology share the common learning development philosophy of building 
knowledge and practice exchange on the foundation of the shared commitment to student learning and development. For example, Case studies 1 and 2 both draw strength and purpose from a multidisciplinary methodology, which is operationalised in vastly different ways but which shares the same relationship between subject and space. Case studies 1 and 3 both prioritise communication and collaboration as a means of learning and take as a starting point the model of a community of practice, with novices and experts challenging each other.

The model is of value to educational and academic developers as well as learning development practitioners and can be used to spot innovation, as well as map it. The model has the capacity to encapsulate a broad range of activity and be used to explore how innovative activity can be grown and expanded, whether that is into another domain or up to a higher level.

More than anything, innovative pedagogies require confident teaching staff willing to take a risk, and there are a number of routes to gaining that confidence. In the spirit of this chapter, the first step has to be collaboration with a colleague.

\section{References}

ALDinHE. (n.d.). About the association for learning development in higher education. Retrieved from http://www.aldinhe.ac.uk/about/

Allan, J. (2013). Staged interventions: Deleuze, arts and education. In I. Semetsky \& D. Masny (Eds.), Deleuze and education (pp. 37-54). Edinburgh, UK: Edinburgh University Press.

Ashforth, B. E. (2012). Role transitions in organisational life: An identity-based perspective. New York, NY: Routledge.

Barnett, R. (2011). Configuring learning spaces: Noticing the invisible. In A. Boddington \& J. Boys (Eds.), Reshaping learning: The future of learning spaces in post-compulsory education (pp. 167-178). Rotterdam, Netherlands: Sense Publishers.

Barton, D., \& Hamilton, M. (1998). Local literacies: Reading and writing in one community. London, UK: Routledge. 
Bennett, S. (2006). First questions for designing higher education learning spaces. The Journal of Academic Librarianship, 33(1), 14-26. https://doi. org/10.1016/j.acalib.2006.08.015

Brundiers, K., Wiek, A., \& Redman, C. L. (2010). Real-world learning opportunities in sustainability: From classroom into the real world. International Journal of Sustainability in Higher Education, 11(4), 308-324. https://doi. org/10.1108/14676371011077540

Callary, B., Werthner, P., \& Trudel, P. (2012). The lived experience of a doctoral student: The process of learning and becoming. The Qualitative Report 17, article 86. Retrieved from https://nsuworks.nova.edu/tqr/vol17/iss43/2

Carnell, E., MacDonald, J., McCallum, B., \& Scott, M. (2008). Passion and politics: Academics reflect on writing for publication. London, UK: Institute of Education.

Dalrymple, J., \& Miller, W. (2006). Interdisciplinarity: A key for real-world learning. Planet, 17(1), 29-31. https://doi.org/10.11120/ plan.2006.00170029

Davis, S. (2015). Transformative learning: Revisiting Heathcote and Vygotsky for the digital age. $p-e-r-f-o-r-m-a-n-c-e 2$ (1-2). Retrieved from http:// www.p-e-r-f-o-r-m-a-n-c-e.org/?p=1835

Dawson, K., \& Lee, B. K. (2018). Drama-based pedagogy: Activating learning across the curriculum. Bristol, UK: Intellect.

Fleer, M., Rey, F. G., \& Veresov, N. (Eds.). (2016). Perezhivanie, emotions and subjectivity: Advancing Vygotsky's legacy. In Perspectives in cultural-historical research (Vol. 1). Springer.

Gardener, H. (2008). The five minds for the future. Studies in Education, 5(1/2), 17-24. Retrieved from http://centre.upeace.org/wp-content/ uploads/2013/04/1.3-Gardner-5-Minds-of-the-Future.pdf

Gourlay, L. (2015). 'Student engagement' and the tyranny of participation. Teaching in Higher Education, 20(4), 402-411. https://doi.org/10.108 $0 / 13562517.2015 .1020784$

Haggis, T. (2009). What have we been thinking of? A critical overview of 40 years of student learning research in higher education. Studies in Higher Education, 34(4), 377-390. https://doi.org/10.1080/03075070902771903

Holley, D., Burns, T., Sinfield, S., \& Glass, B. (2011). When worlds collide: The paradox of learning development, e-learning and the 21st-century university. In P. Hartley, J. Hilsdon, C. Keenan, S. Sinfield, \& M. Verity (Eds.), Learning development in higher education (pp. 199-211). Basingstoke, UK: Palgrave Macmillan. 
Hwang, G.-J., Chang, S.-C., Chen, P.-Y., \& Chen, X.-Y. (2018). Effects of integrating an active learning-promoting mechanism into location-based realworld learning environments on students' learning performances and behaviors. Educational Technology Research and Development, 66, 451-474. https://doi.org/10.1007/s11423-017-9567-5

Jamieson, P., Dane, J., \& Lippman, P. C. (2005). Moving beyond the classroom: Accommodating the changing pedagogy of higher education. Refereed proceedings of 2005 Forum of the Australasian Association for Institutional Research (pp. 17-23). Retrieved from http://www.aair.org.au/app/webroot/media/ pdf/AAIR\%20Fora/Forum2005/Jamieson.pdf

Jennings, G., Cater, C. I., Hales, R., Kensbock, S., \& Hornby, G. (2015). Partnering for real world learning, sustainability, tourism education. Quality Assurance in Education, 21(4), 378-394. https://doi.org/10.1108/ QAE-03-2015-0010

Kreber, C. (2013). Authenticity in and through teaching in higher education. London, UK: Routledge.

Lambropoulos, N., Faulkner, X., \& Culwin, F. (2012). Supporting social awareness in collaborative e-learning. British Journal of Educational Technology, 43(2), 295-306. https://doi.org/10.1111/j.1467-8535.2011.01184.x

Lave, J., \& Wenger, E. (1991). Situated learning: Legitimate peripheral participation. Cambridge, UK: Cambridge University Press.

Lea, M. (2004). Academic literacies: A pedagogy for course design. Studies in Higher Education, 29(6), 739-756. https://doi.org/10.1080/03075070 42000287230

Lea, M., \& Stierer, B. (Eds.). (2000). Student writing in higher education: New contexts. Higher Education, 40(3), 373-374.

Lea, M., \& Street, B. (1998). Student writing and staff feedback in higher education: An academic literacies approach. Studies in Higher Education, 23(2), 157-172.

Lea, M., \& Street, B. (2000). Student writing and staff feedback in higher education: An academic literacies approach. In M. Lea \& B. Stierer (Eds.), Student writing in higher education. Buckingham, UK: Open University Press. Lenten, A. P., Slabu, L., Sedikides, C., \& Power, K. (2013). I feel good, therefore I am real: Testing the causal influence of mood on state authenticity. Cognition and Emotion, 27(7), 1202-1224. https://doi.org/10.1080/0269993 1.2013 .778818 
Lindgren, R., \& McDaniel, R. (2011). Transforming online learning through narrative and student agency. Educational Technology \& Society, 15(4), 344-355.

Lock, J., Kim, B., Koh, K., \& Wilcox, G. (2018). Navigating the tensions of innovative assessment and pedagogy in higher education. The Canadian Journal for the Scholarship of Teaching and Learning, 9(1). https://doi. org/10.5206/cjsotl-rcacea.2018.1.8

McDonald, M., \& Wearing, S. (2013). A reconceptualization of the self in humanistic psychology: Heidegger, Foucault and the sociocultural turn. Journal of Phenomenological Psychology, 44, 37-59. https://doi. org/10.1163/15691624-12341244

Molderez, I., \& Fonseca, E. (2017). The efficacy of real-world experiences and service learning for fostering competences for sustainable development in higher education. Journal of Cleaner Production, 172, 4397-4410. https:// doi.org/10.1016/j.jclepro.2017.04.062

Moodle. (2012). Philosophy. Retrieved from https:/docs.moodle.org/29/en/ Philosophy

Moore, S. (2003). Writers' retreats for academics: Exploring and increasing the motivation to write. Journal of Further and Higher Education, 27(3), 333-342. https://doi.org/10.1080/0309877032000098734

Murray, R., \& Newton, M. (2009). Writing retreat as structured intervention: Margin or mainstream? Higher Education Research and Development, 28(5), 527-539. Retrieved from https://www.tandfonline.com/doi/ full/10.1080/07294360903154126

Quigley, C. (2014). Expanding our view of authentic learning: Bridging in and out-of-school experiences. Cultural Studies of Science Education, 9, 115-122. Repko, A., Szostak, R., \& Buchberger, M. (2017). Introduction to interdisciplinary studies (2nd ed.). Los Angeles, CA: Sage. Retrieved from https://brandon. multics.org/library/macintyre/macintyre2002education.pdf

Rey, F.G. (2016). Vygotsky's concept of Perezhivanie in the psychology of art and at the final moment of his work: Advancing his legacy. Mind, Culture, and Activity 23(4): Symposium on Perezhivanie. Retrieved from http://www. tandfonline.com/doi/abs/10.1080/10749039.2016.1186196?journa lCode $=$ hmca20

Sagayadevan, V., \& Jeyaraj, S. (2012). The role of emotional engagement in lecturer-student interaction and the impact on academic outcomes of student achievement and learning. Journal of the Scholarship of Teaching and Learning, 12(3), 1-30. 
Sinfield, S., Holley, D., Burns, T., Hoskins, K., O’Neill, P., \& Harrington, K. (2011). Raising the student voice: Learning development as socio-political practice. In P. Hartley, J. Hilsdon, C. Keenan, S. Sinfield, \& M. Verity (Eds.), Learning development in higher education (pp. 53-63). Basingstoke, UK: Palgrave Macmillan.

Street, B. (1984). Literacy in theory and practice. Cambridge, UK: Cambridge University Press.

Street, B. (1993). Cross-cultural approaches to literacy. Cambridge, UK: Cambridge University Press.

Stroh, K. M. (2015). Intersubjectivity of Dasein in Heidegger's being and time: How authenticity is a return to community. Human Studies, 38, 243-259.

Temple, P. (2008). Learning spaces in higher education: An under-researched topic. London Review of Education, 6(3), 229-241. https://doi. org/10.1080/14748460802489363

Theodosiou, M., Rennard, J.-P., \& Amir-Aslani, A. (2012). Theory to practice: Real-world case-based learning for management degrees. Nature Biotechnology, 30(9), 894-895.

Xerri, M. J., Radford, K., \& Shacklock, K. (2018). Student engagement in academic activities: A social support perspective. Higher Education, 75, 589-605. https://doi.org/10.1007/s10734-017-0162-9

Zepke, N. (2015). Student engagement research: Thinking beyond the mainstream. Higher Education Research \& Development, 34(6), 1311-1323. https://doi.org/10.1080/07294360.2015.1024635

Open Access This chapter is licensed under the terms of the Creative Commons Attribution 4.0 International License (http://creativecommons.org/ licenses/by/4.0/), which permits use, sharing, adaptation, distribution and reproduction in any medium or format, as long as you give appropriate credit to the original author(s) and the source, provide a link to the Creative Commons licence and indicate if changes were made.

The images or other third party material in this chapter are included in the chapter's Creative Commons licence, unless indicated otherwise in a credit line to the material. If material is not included in the chapter's Creative Commons licence and your intended use is not permitted by statutory regulation or exceeds the permitted use, you will need to obtain permission directly from the copyright holder.

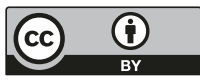

